\title{
Aspects of Selective Laser Melting Technology Considered in the Preparation of Trabecular Structures for Bone Tissue Substitution
}

\author{
Michaela Roudnicka ${ }^{1}$, Dalibor Vojtech ${ }^{1}$, Matej Daniel ${ }^{2}$ \\ ${ }^{1}$ Department of Metals and Corrosion Engineering, Faculty of Chemical Technology, University of Chemistry and \\ Technology Prague, Technicka 5, 16628 Prague 6. Czech Republic. E-mail: michaela.roudnicka@vscht.cz, voj- \\ techd@vscht.cz \\ ${ }^{2}$ Department of Mechanics, Biomechanics and Mechatronics, Czech Technical University, Technicka 4, 16607 \\ Prague 6. Czech Republic. E-mail: matej.daniel@fs.cvut.cz
}

In this paper, the possibilities of selective laser melting (SLM), one of metal additive manufacturing technologies, in the preparation of trabecular structures are discussed. Despite great advantages in geometrical freedom, there are specific process-inherent aspects that must be considered before the production of such structures. To verify SLM capabilities, we tested different orientations (horizontal and vertical) and thicknesses $(0.2-4.0 \mathrm{~mm})$ of single struts. Significant irregularities in strut thickness and deviations from the designed cross-sectional area were observed. Horizontal struts showed greater geometrical deviations. Based on our observations, a trabecular structure was prepared with all struts inclined $45^{\circ}$ from the building platform. Due to the $72 \%$ porosity, mechanical properties approached those of the bone, which is beneficial for the application of such structure in orthopaedics for bone tissue substitution.

Keywords: additive manufacturing, SLM, Ti6Al4V, bone, trabecular structure

\section{Introduction}

Nowadays, bone and joint replacement surgeries are being performed with a higher rate due to the increase of the average population age and more active lifestyle. Consequently, implants with improved performance are demanded. Especially in young patients who expose implants to greater mechanical stress over a longer period of time, implant longevity is desired to avoid reoperations necessary in case of implant failure [1].

Metals are the best choice for load-bearing implants because of their suitable mechanical properties. Among other biocompatible metals (e.g. stainless steel, cobalt alloys), titanium and its alloys are preferred thanks to their good stiffness-to-weight ratio and exceptional corrosion resistance. Appropriate stiffness of an implant is the main prerequisite for its reliability and durability [2].

Only fully dense metallic implants have been used for the replacement and stabilization of damaged bone tissue until recently; however, such implants have suffered from aseptic loosening or complete failure due to the stress-shielding effect. The stress-shielding effect results from the significantly higher elastic modulus of an implant that causes the nearby bone to be loaded insufficiently [3]. Consequently, bone resorbs, which leads to micromovements of an implant at the bone-implant interface and eventual premature failure. A lack of interfacial bonding arises also from the fact that commonly used biometals are inert, so do not chemically bond with the bone tissue. Only mechanical fixation is thus provided. To enhance the fixation, two approaches are possible: (1) an appropriate surface treatment inducing bioactivity (bonding of material with bone tissue); and/or (2) a favourable implant structure allowing the bone tissue to grow into the material, thus providing biological fixation [1].

Regarding the above-mentioned problems faced by orthopaedic surgery, cellular metals offer a promising solution. With porosity introduced to the material, effective implant stiffness is reduced; at a suitable porosity degree, a bone-like stiffness can be even achieved. Also, bone tissue is allowed to grow into the implant if open pores are available [4].

Despite a large number of techniques allowing preparation of metallic porous structures, additive manufacturing (AM) has been a breakthrough [5]. It enables to create net-shape objects while allowing to control their internal structure in each part of their volume. A wide range of cell morphologies can be applied to obtain highly porous cellular structures [6]. Mechanical properties of such structures can be finely tuned to match that of a particular patient's bone. Future expectations are accurate copies of bone tissue mapped by medical imaging techniques (e.g. CT, MRI) [7]. Selective Laser Melting (SLM) studied in this paper is one of the AM technologies, which works on the principle of selective melting of powdered metal by a laser beam [8].

SLM has been already applied for the preparation of porous structures from biocompatible metals. 
Many cell morphologies were investigated (e.g. cubic $[9,10]$, octahedron [11], rhombic dodecahedron [12], gyroid [11, 13]), their mechanical properties were measured $[12,14]$, and biocompatibility was verified by in vitro $[15,16]$ or even in vivo tests $[17,18]$. However, not many papers have dealt with studies of single struts forming the trabecular structure. Weißmann et al. [19] compared the effect of two AM technologies - SLM and electron beam melting (EBM) - in performance of single struts. However, the study was done on specimens consisting of four struts. Round struts with $0^{\circ}$ and $45^{\circ}$ inclination were tested, with diameters between 1.1 and $1.7 \mathrm{~mm}$ only. Weißmann et al. demonstrated higher accuracy of SLM struts, related to the generally higher roughness of EBM specimens. Also two studies on solely EBM appeared [20, 21]. Therefore, our goal was to extend the data in this weakly researched area of single struts preparation, to characterize the structure and properties of the prepared struts and to use these findings as a basis for future modelling of specific trabecular structures.

In this paper, we report the results of the initial study aimed at describing specific process-inherent aspects that must be considered before the production of trabecular structures by SLM. To verify SLM capabilities, we tested different orientations and thicknesses of single struts being the cornerstones of trabecular structures. Surface condition and geometrical precision were evaluated. Consequently, based on our observations, an entire trabecular structure was produced and its mechanical performance was tested.

\section{Materials and Methods}

\subsection{Design of struts}

As a starting step for the development of trabecular structures, single struts were designed. To be directly usable for the evaluation of mechanical properties in tension, the struts were designed in the shape of flat tensile specimens (technical drawing in Fig. 1a). The width of the struts was kept at a constant value of $0.5 \mathrm{~mm}$. Values of the gage thickness ranged from 0.2 to $4.0 \mathrm{~mm}$.

To assess the influence of strut inclination with respect to the building direction, two basic orientations were used for this initial study: vertical and horizontal. For a clear idea, the relation between the strut orientation and the building direction is schematically shown in Fig. 1b. For horizontal orientation, only struts with a width of $0.5 \mathrm{~mm}$ and higher were printed successfully. Thinner struts deformed by the action of thermally-induced stresses.

After the characterization of the single struts, a whole trabecular structure with a rhombic dodecahedron unit cell. The struts were designed $0.24 \mathrm{~mm}$ in thickness and $1 \mathrm{~mm}$ in length. The structure was oriented in such a way that all struts were inclined by $45^{\circ}$ with respect to the SLM building plate.

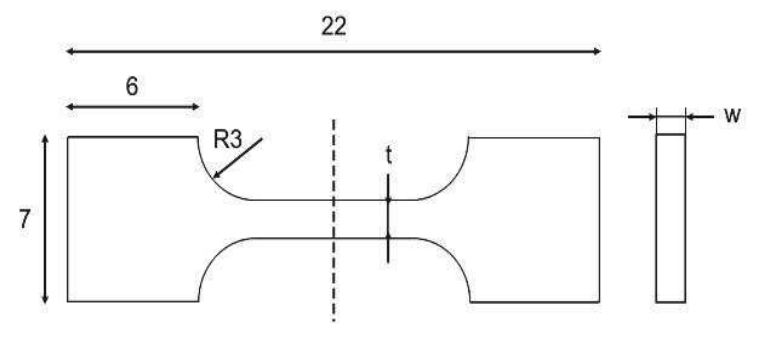

a)

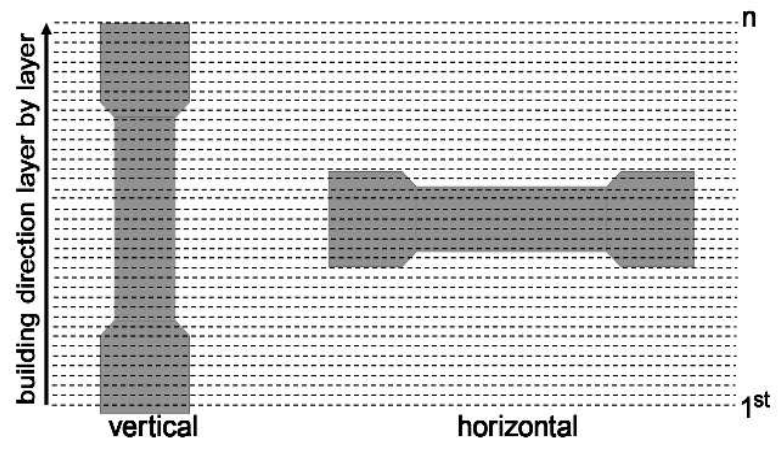

b)

Fig. 1 (a) Technical drawing of a single strut designed in the form of a tensile specimen (t is a varying thickness and $w$ is a width of $0.5 \mathrm{~mm}$ ), (b) Schematics for vertical and horizontal orientations

\subsection{Selective laser melting}

The designed struts as well as the trabecular structure were produced using an M2 Cusing SLM machine (ConceptLaser, Germany) equipped with one 200W fibre Yb-YAG laser. A gas-atomized powder of Ti grade 2 (CL 42Ti, ConceptLaser) was selected as the testing material because titanium is the gold standard for the production of orthopaedic implants or lightweight components for aviation industry. Laser melting was carried under a protective argon atmosphere with $\mathrm{O}_{2}$ content less than 0.5 vol.\%. Laser power was set to $200 \mathrm{~W}$. The struts were produced in layers of 30 $\mu \mathrm{m}$ in thickness.

\subsection{Evaluation of dimensional inaccuracies}

Dimensional inaccuracies were evaluated by mechanical and optical measurement. Mechanical measurement by digital electronic caliper Mitutoyo provided information about the average thickness and width of each strut. Dimensional error was calculated as the ratio between the actual average dimensions and the designed dimensions. Variances in thickness along the whole strut length were observed on images obtained by a scanning electron microscope (SEM) Tescan VEGA-3 LMU. Geometrical deviations of each strut were then established using image analysis (ImageJ software) as the maximum deviations from the average thickness. 


\subsection{Evaluation of mechanical properties}

Mechanical properties of the prepared trabecular structure were measured under compressive loading using a universal loading machine LabTest 5.250SP1VM. Measurement was carried out at room temperature at a deformation rate of $0.001 \mathrm{~s}^{-1}$. Four cubic specimens $(\mathrm{a}=5 \mathrm{~mm})$ were tested. Tensile properties of individual struts were measured at our partner institution by specialized miniature tensile tests and are the content of another publication.

\section{Results and Discussion}

To understand the building of trabecular structures by SLM and their properties, this work deals with only single struts being their cornerstones. Average trabeculae thickness in humans ranges between 60 and 200 $\mu \mathrm{m}(\sim 60 \mu \mathrm{m}$ for iliac trabecular bone [22], 180-200 $\mu \mathrm{m}$ for metacarpal head [23]). Such low dimensions are already at the edge of SLM resolution. Therefore, thicknesses in the range from $0.2 \mathrm{~mm}$ to $4 \mathrm{~mm}$ were studied to identify general trends.

\subsection{Differences between vertical and horizontal struts}

The orientation of struts in the SLM chamber influences the building process and surface characteristics of struts. Figure 1b schematically shows that vertical struts are formed by a much higher number of layers. However, the area melted by laser beam in each layer is significantly lower. Conversely, horizontal struts are built in less layers, but of much larger area.

The difference in specimen area per layer and number of layers yields also differences in specimen surface. The characteristic surfaces of the vertical and horizontal struts are displayed in Fig. 2. In both cases, spherical particles adhering to the surface are observed. The diameters of these spheres fall into the range of powder size distribution, which suggests that the adherent spheres are unmelted particles of input powder that adhere to the strut surface by thermal diffusion effects or partial melting [24]. Very small spheres can be attributed to the 'balling' effect, which is associated with melt pool inconsistency and changes of wettability [25]. Such particles are more abundant in horizontal struts (Fig. 2b), where longer scan vectors yield in lower residual heat effect, lower temperature of a melt pool and thus decrease in melt flowability [26].

Beneath the adherent spherical particles, smooth surface with overlapping melt pools can be observed. In horizontal struts (Fig. 2b), the melt pools are shallower because heat dissipation by previously solidified material is higher with larger specimen area per layer. That results in lower line energy and so lower melt pool depth [27]. Moreover, for shorter scan vector length, preheating from one vector to his adjacent neighbour yields deeper melt pool penetration and a larger heat affected zone [28].
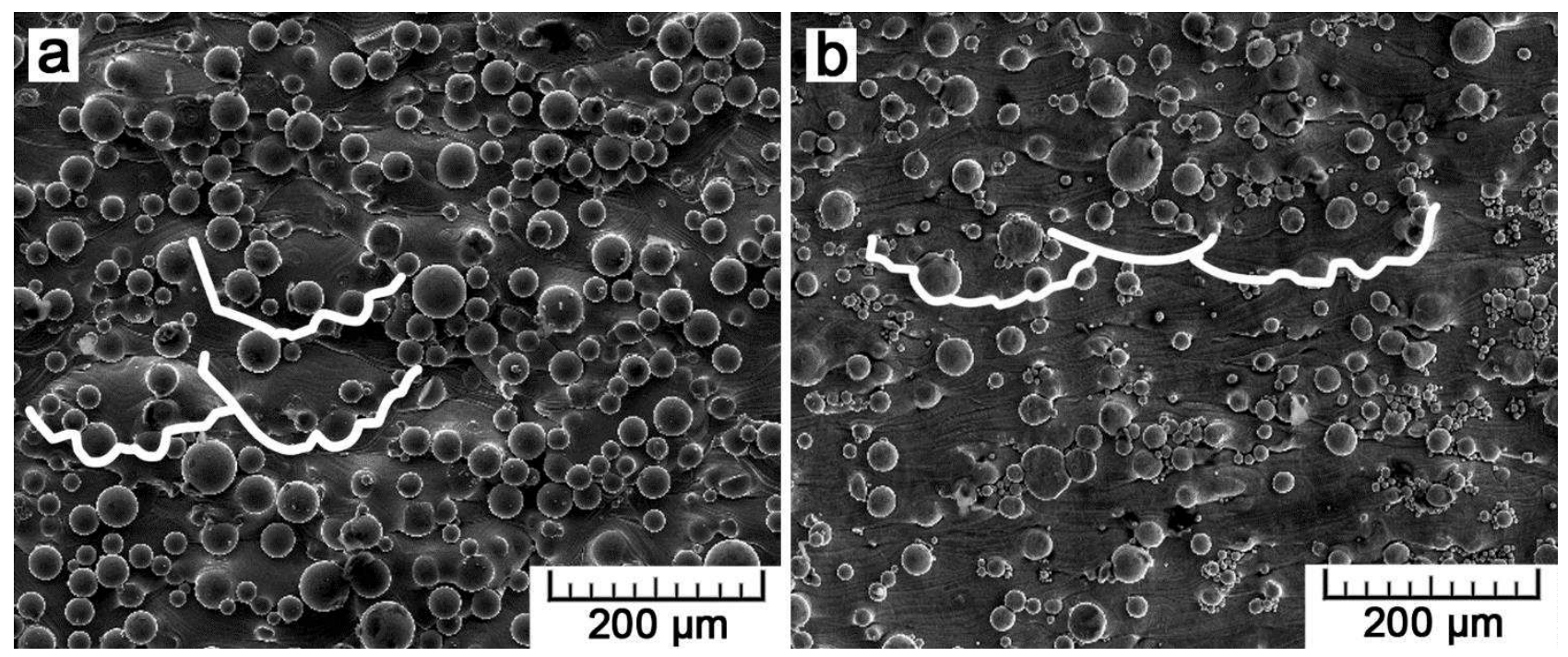

Fig. 2 Surface of (a) vertical and (b) horizontal struts. White lines indicate melt pools. The images are oriented in the building direction layer by layer.

Last but not least, specimen orientation influences the formation of defects. The most common type of defects present in SLM Ti-6Al-4V alloy are so-called lack-of-fusion (LOF) defects. Such voids result from inappropriate interconnection of a melted material between individual successive layers and/or adjacent scan tracks. The LOF can be attributed to non-optimal set-up of process parameters resulting in melt pool width lower than the hatching distance or melt pool depth lower than the layer size. However, there might be also other effects that can disturb the thermal field [29, 30]. It has been shown [31] that irregularities formed by laser melting at the top of each layer can gradually accumulate during sample build-up layer by layer and then, at some point, defects are formed in between certain layers. If we consider only interlayer 
defects, we can say that larger defects are formed in horizontally built samples with respect to the larger interfaces between layers. The larger the area melted in one layer, the higher is the probability of melt disturbances, accumulation of irregularities and formation of defects. An extreme example of such interlayer LOF

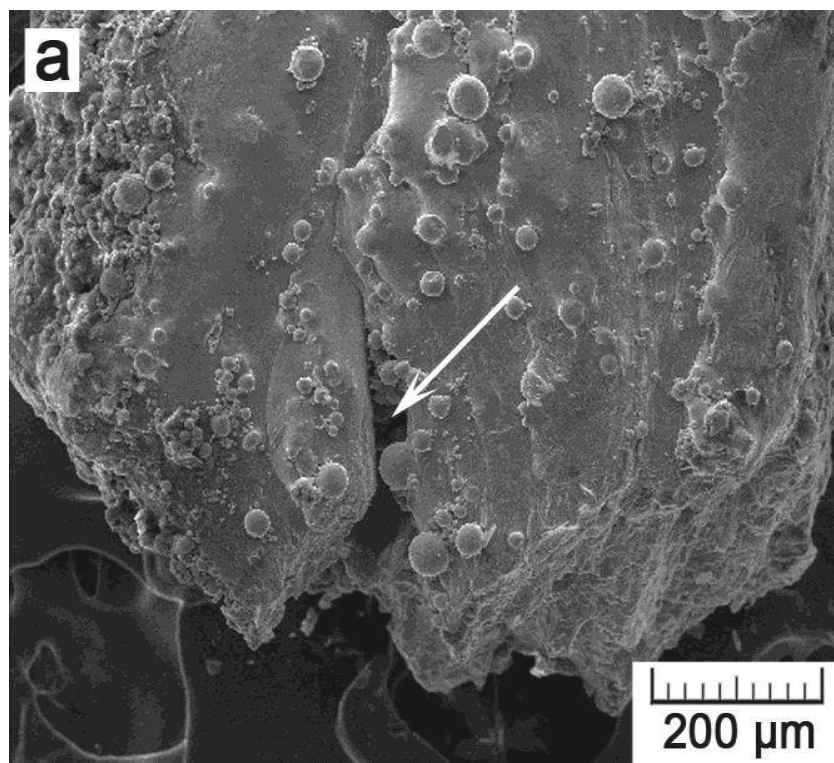

defect is given in Fig. 3. In this case, defects accumulated in between layers approximately in the middle of the strut (Fig. 3a) and led to the interconnection between these layers almost across the whole strut length. Therefore, a channel-like void was observed on the fracture surface (Fig. 3b).

Fig. $3 \mathrm{LOF}$ defect in between layers of a horizontal strut

\subsection{Dimensional inaccuracies}

Due to the low thickness of single struts, close to the resolution limit of SLM, dimensional inaccuracies pronounce significantly. Although the width of all struts was designed as $0.5 \mathrm{~mm}$, the actual widths varied. The average error in width value was $8 \%$ for ver-

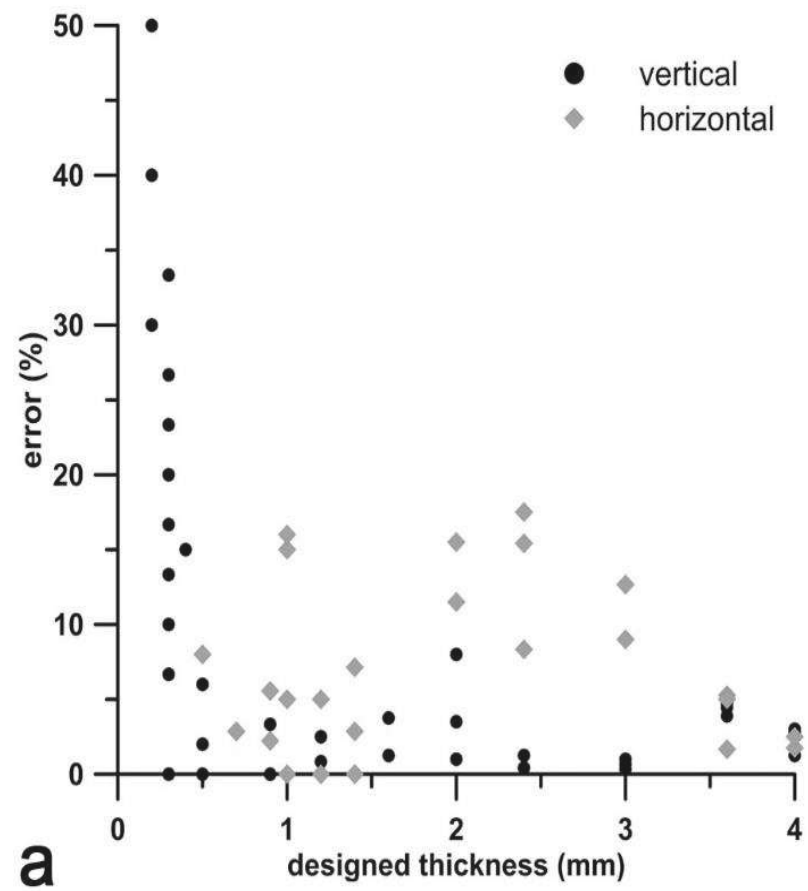

tical struts and $22 \%$ for horizontal struts. Furthermore, Fig. 4a visualises errors in thickness for the struts of all designed thicknesses. It is clear that the errors are higher for horizontal struts. Similar conclusion was drawn by Hanzl et al. [32]. Therefore, considering the errors in both dimensions, total errors in cross-sectional area (Fig. 4 b) can reach up to $50 \%$.

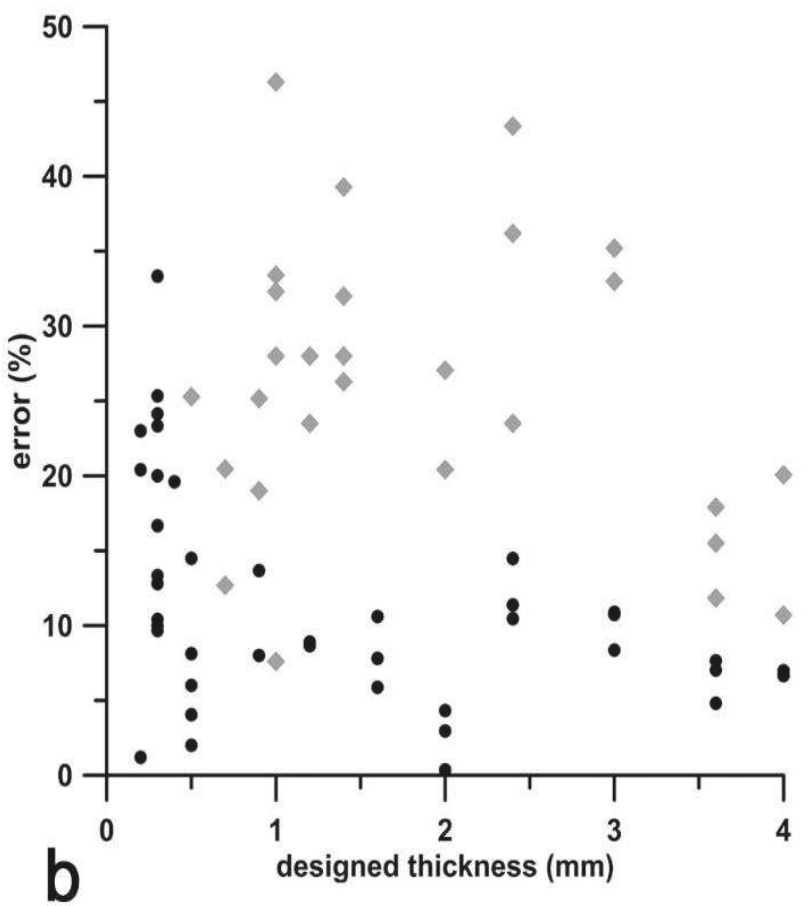

Fig. 4 Dimensional errors in (a) the thickness and (b) total cross-sectional area of the studied struts 
The reason for the higher dimensional inaccuracy of horizontal struts can be explained by their orientation within the 'powder bed'. Powder particles that get into touch with a hot melt adhere to the final solidified part, as it is shown in Fig. 2. That occurs at the lower base of 3D-printed parts and along their entire surface. The lower base of products built by SLM has the lowest surface quality. That can be explained by the direct contact of hot melt with loose powder. Moreover, under the action of gravity, the melt flows into a free space in between loose powder particles and so a larger volume of loose powder is affected. What concerns the circumference of SLM parts, a contour laser track that set bounds of each layer can partially melt adjacent powder particles and adhesion by thermal diffusion takes place, too. Therefore, in case of vertical struts, adhered particles can be observed along the whole circumference and in case of those horizontal, predominantly on one side; the one which represents the lower base.

Great scattering of the data in the charts in Fig. 4 can be noticed. Such scattering tells of the low repeatability of the SLM process in case of thin struts. The cause may be the different location of struts in the SLM chamber. The SLM chamber is virtually divided

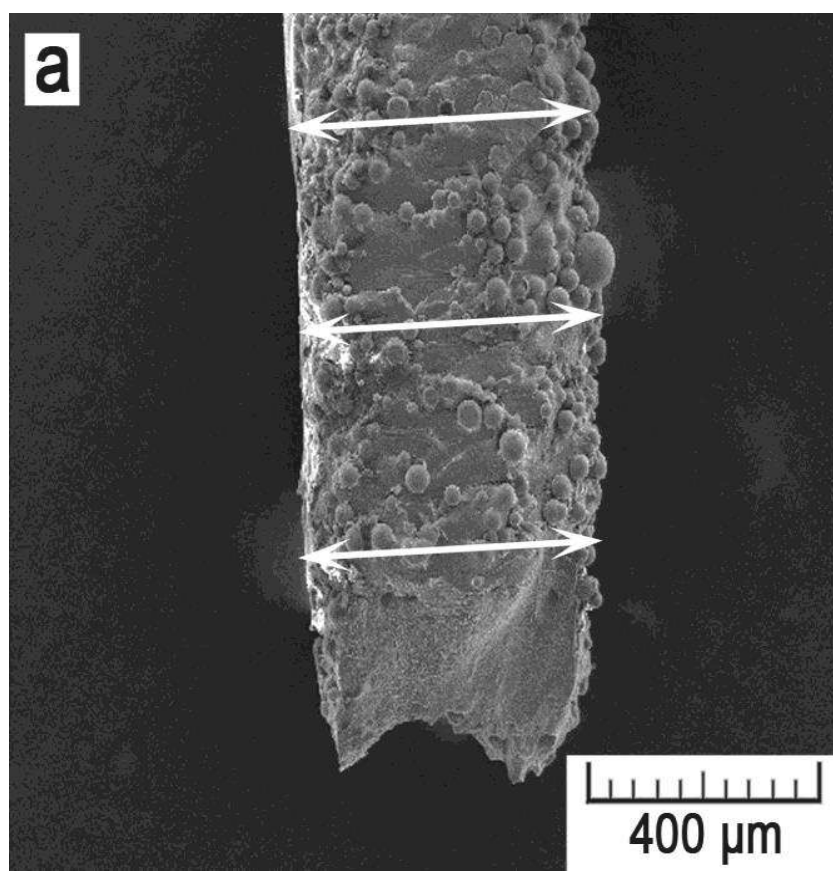

into a chess-board with a square size of $5 \times 5 \mathrm{~mm}^{2}$. If a strut is located inside one square, it is melted continuously in one scanning step. However, if it is spread between two squares, then it is melted in two separate steps. That may yield in higher dimensional inaccuracy. Also, some irregularities in the uniform distribution of powder layers during powder raking, inert gas feed and other hardly predictable conditions may play their role. The thinnest struts $(0.2$ and $0.3 \mathrm{~mm})$ shows the largest scattering because we move around the edge of SLM resolution and so the SLM result is unpredictable. Figure 4 have shown that some struts were printed almost precisely, while others deviated from their designed dimension by almost $50 \%$.

When we look at single struts, even irregularities in the uniform shape can be observed. Two examples of a horizontal and a vertical strut are given in Fig. 5. While vertically built struts are more or less regular in shape (Fig. 5a), geometrical irregularities in horizontally built struts are obvious; the thickness of the horizontal struts varies over their length (indicated in Fig. $5 b)$. We determined deviations from average thickness values and summarized them into a chart shown in Fig. 6a. The deviations decrease with increasing dimensions.

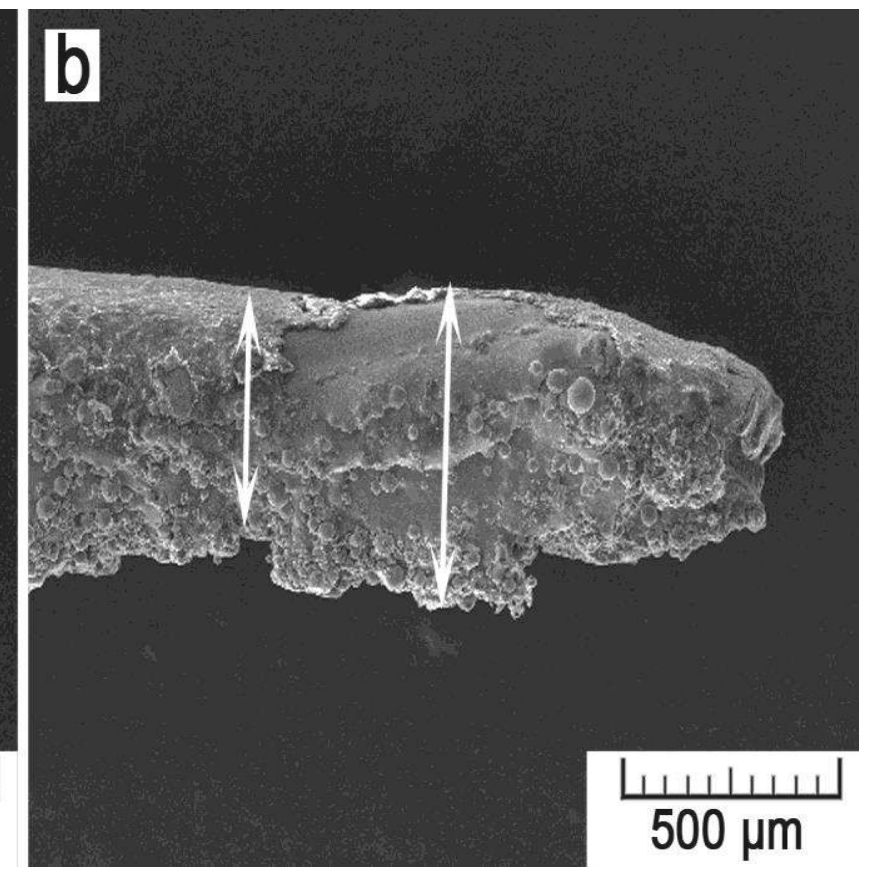

Fig. 5 Geometrical inaccuracies of (a) vertical and (b) horizontal struts

The first source of these deviations is the additive manufacture itself due to the gradual processing of input material. For the ideal state, we can model logical deviations using an assumption that the laser beam forms a spot of $200 \mu \mathrm{m}$ in diameter and the spot moves by a hatching distance of $80 \mu \mathrm{m}$. The minimal thickness of struts is thus $200 \mu \mathrm{m}$; such struts are formed by a single scan vector. For larger products, the thickness is gradually increased by steps of $80 \mu \mathrm{m}$ because the laser scanning is always accomplished in a definite number of scan vectors. If a strut of $0.3 \mathrm{~mm}$ in thickness is about to be produced, 3 scan vectors are necessary. However, 3 vectors will result in a thickness of $360 \mu \mathrm{m}$ (1st vector $\rightarrow 200 \mu \mathrm{m}$, 2nd vector $\rightarrow$ $280 \mu \mathrm{m}, 3 \mathrm{rd}$ vector $\rightarrow 360 \mu \mathrm{m})$. The difference between the designed and obtained thickness is thus 60 $\mu \mathrm{m}$, which already yields a logical error of $20 \%$. With increasing thickness, the error decreases (see Fig. 6b). 
Specimens of certain thickness values can be theoretically printed precisely; such values are represented by local minima in the graph. However, in reality, the spot size may be different based on thermal conditions dictated by the combination of numerous process parameters.
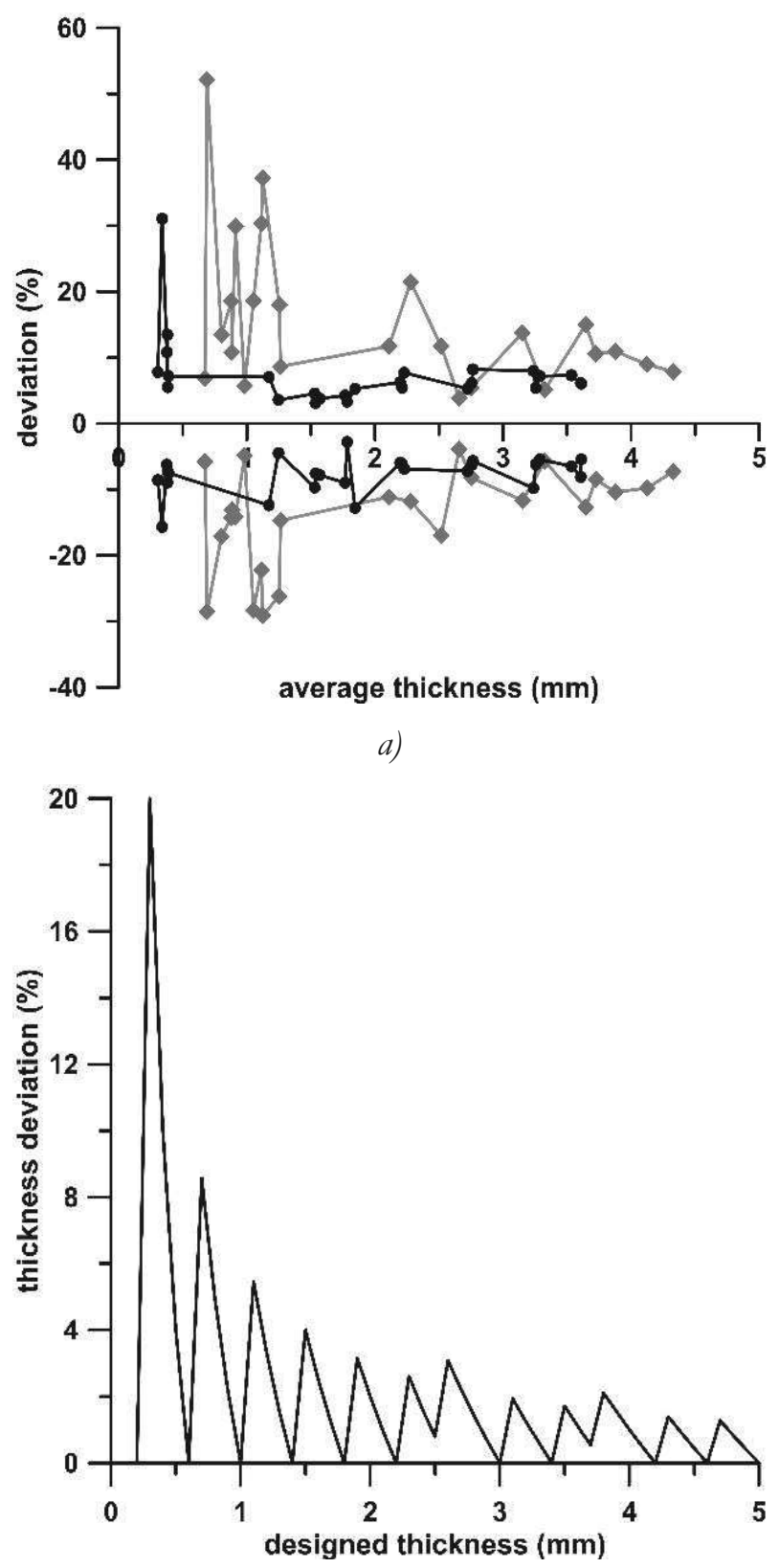

b)

Fig. 6 Deviations in strut thickness: (a) calculated from the average thickness value, (b) model deviations from designed thickness values given by laser hatching (here for $h=80 \mu \mathrm{m}$ )

The general trend of the deviation evolution with increasing thickness in Fig. 6a is similar to that in Fig. 6b. Positions of local minima are comparable. Nevertheless, the deviations are more pronounced. In vertical struts, the deviations are increased by adhered powder particles and melt pools overlapping between adjacent layers. In horizontal struts, the deviations from required dimensions are strongly increased by the unevenness of the lower struts base caused by overhangs of solidified melt with large amount of affected powder particles adhering to them.

Based on the observed deviations, it can be expected that also mechanical properties of single struts will show certain deviations from expected values. Such deviations will be more pronounced in case of horizontal struts in logical agreement with their lower geometrical accuracy. Also, the thinner the struts, the larger will be the influence of uneven surface with adherent powder particles. Figure 6a has shown that in thin horizontal struts the geometrical deviation can reach up to $|30-50| \%$. If there is a local reduction in load-bearing area by $50 \%$, a strut will be first plastically deformed in this weakest part and so its yield strength will be reduced to a half value. In vertical struts, the surface is more regular. Local deviations keep below $10 \%$ for all thicknesses above $0.5 \mathrm{~mm}$. Therefore, the surface would not effect mechanical properties so significantly.

\subsection{Trabecular structure}

Figure 7 shows a SEM image of the prepared trabecular structure. Similarly to single struts (Fig. 2), many adherent powder particles are visible on the strut surface. Consequently, the actual average strut thickness was higher than the designed one. The strut thickness was determined by optical measurement as $0.38 \pm 0.03 \mathrm{~mm}$. The total porosity was then determined gravimetrically as $72.3 \%$.

Trabecular bone reaches porosity in the range of 50-90\%. Depending on the porosity, yield strength values can be attained from 4 to $12 \mathrm{MPa}$ [33]. The measurement of mechanical properties provided the value of compressive yield strength of $55.3 \pm 1.7 \mathrm{MPa}$. The trabecular structure collapsed at a stress of $80.7 \pm 2.1 \mathrm{MPa}$. Then, the compressive stress-strain curves showed a plateau and a stress increase due to the compaction characteristic for trabecular structures [34]. Compared to fully dense titanium showing a yield strength of $560 \pm 5 \mathrm{MPa}$ [35], introducing porosity have brought about a tenfold decrease in yield strength. Comparably, the elastic modulus decreased from $110 \mathrm{GPa}$ (ASTM B265) to 0.98 $\pm 0.09 \mathrm{GPa}$. Such stiffness is already suitable for replacement of trabecular bone which elastic modulus can reach 0.1-5 GPa [36]. 

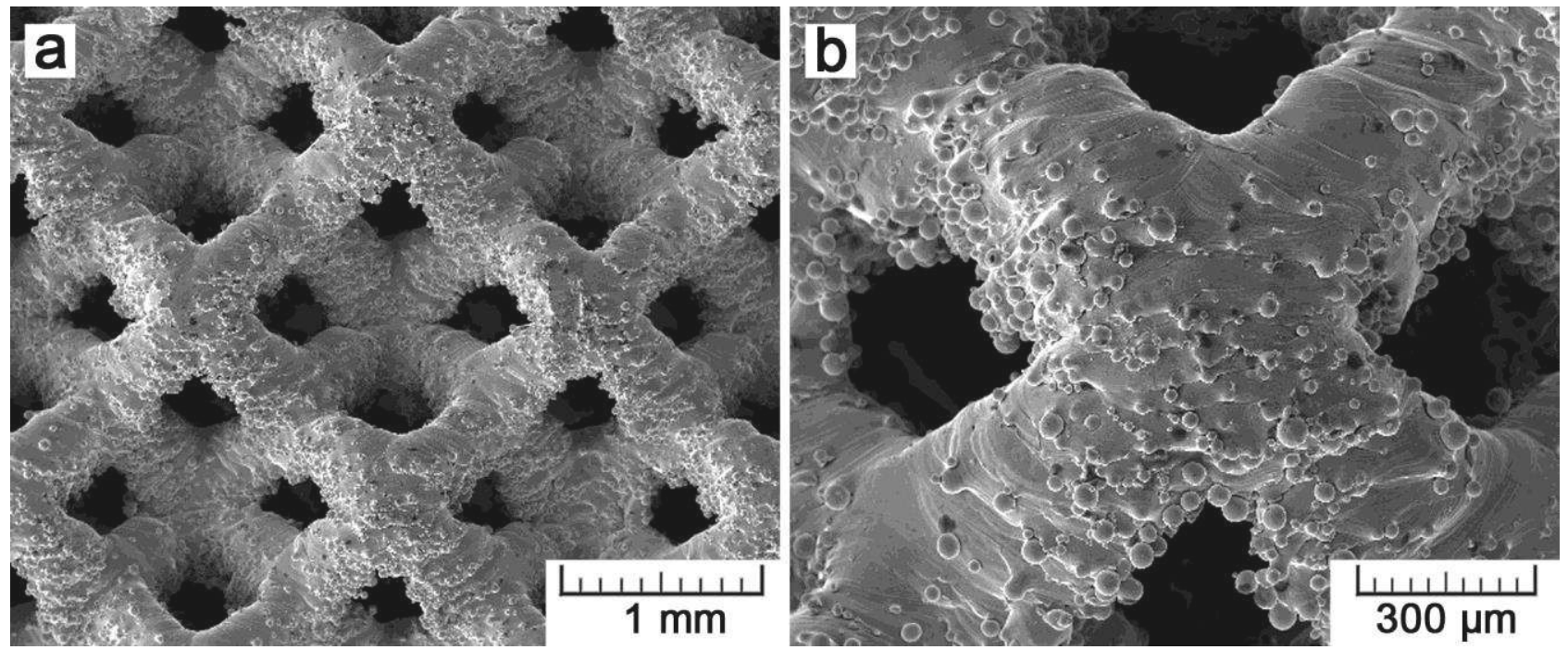

Fig. 7 Prepared trabecular structure

\section{Conclusions}

The preparation of single struts and their examination have manifested significant deviations of actual struts dimensions over those designed. Studying the range of different strut thicknesses revealed that geometrical inaccuracies pronounce more and more with lower cross-sectional area of struts. When strut orientation is considered, higher dimensional deviations occur in horizontal struts compared to those vertical. Based on these observations, general recommendations for the development of trabecular structures can be drawn. If possible, it is suggested to orientate trabecular structures in such a manner that their struts are preferentially oriented vertically, so that the geometrical deviations are minimized and better mechanical performance can be expected. In this work, we prepared a trabecular structure in which all struts were inclined by $45^{\circ}$ with respect to the SLM building plate. Porosity of $72.3 \%$ led to a tenfold decrease in the elastic modulus and compressive yield strength of dense titanium so that it approached mechanical properties of trabecular bone.

\section{Acknowledgement}

This work was supported by the Czech Science Foundation (projects no. P108/12/G043 and 1614758S). Thanks Prospon spol. company for providing the testing material.

\section{References}

[1] BANDYOPADHYAY, A., ESPANA, F., BALLA, V. K., BOSE, S., OHGAMI, Y., DAVIES, N. M. (2010). Influence of porosity on mechanical properties and in vivo response of Ti6Al4V implants. In: Acta Biomaterialia, Vol. 6, No. 4, pp. 1640-1648.
[2] WANG, X., XU, S., ZHOU, S., XU, W., LEARY, M., CHOONG, P., QIAN, M., BRANDT, M., XIE, Y. M. (2016). Topological design and additive manufacturing of porous metals for bone scaffolds and orthopaedic implants: A review. In: Biomaterials, Vol. 83, pp. 127-141.

[3] DALlago, M., FONTANARI, V., WINIARSKI, B., ZANINI, F., CARMIGNATO, S., BENEDETTI, M. (2017). Fatigue properties of Ti6Al4V cellular specimens fabricated via SLM: CAD vs real geometry. In: Procedia Structural Integrity, Vol. 7, pp. 116-123.

[4] HEINL, P., ROTTMAIR, A., KÖRNER, C., SINGER, R. F. (2007). Cellular Titanium by Selective Electron Beam Melting. In: Advanced Engineering Materials, Vol. 9, No. 5, pp. 360-364.

[5] MURR, L. E. (2017). Open-cellular metal implant design and fabrication for biomechanical compatibility with bone using electron beam melting. In: Journal of the Mechanical Behavior of Biomedical Materials, Vol. 76, pp. 164-177.

[6] HANZL, P., ZETKOVA, I., DANA, M. (2017). Issues of Lattice Structures Production via Metal Additive Manufacturing. In: Manufacturing Technology, Vol. 17, No. 6.

[7] TAN, X. P., TAN, Y. J., CHOW, C. S. L., TOR, S. B., YEONG, W. Y. (2017). Metallic powderbed based 3D printing of cellular scaffolds for orthopaedic implants: A state-of-the-art review on manufacturing, topological design, mechanical properties and biocompatibility. In: Materials Science and Engineering: C, Vol. 76, pp. 1328-1343. 
[8] SEBASTIAN, B., WILHELM, M., ANDREI, D. (2012). Selective Laser Melting. In: Laser Technik Journal, Vol. 9, No. 2, pp. 33-38.

[9] XU, S., SHEN, J., ZHOU, S., HUANG, X., XIE, Y. M. (2016). Design of lattice structures with controlled anisotropy. In: Materials \& Design, Vol. 93, pp. 443-447.

[10] DALLAGO, M., FONTANARI, V., TORRESANI, E., LEONI, M., PEDERZOLLI, C., POTRICH, C., BENEDETTI, M. (2018). Fatigue and biological properties of Ti-6Al-4V ELI cellular structures with variously arranged cubic cells made by selective laser melting. In: Journal of the Mechanical Behavior of Biomedical Materials, Vol. 78, pp. 381-394.

[11] SPEIRS, M., VAN HOOREWEDER, B., VAN HUMBEECK, J., KRUTH, J. P. (2017). Fatigue behaviour of NiTi shape memory alloy scaffolds produced by SLM, a unit cell design comparison. In: Journal of the Mechanical Behavior of Biomedical Materials, Vol. 70, pp. 53-59.

[12] FOUSOVA, M., VOJTECH, D., KUBASEK, J., JABLONSKA, E., FOJT, J. (2017). Promising characteristics of gradient porosity Ti-6Al$4 \mathrm{~V}$ alloy prepared by SLM process. In: Journal of the Mechanical Behavior of Biomedical Materials, Vol. 69, pp. 368-376.

[13] YÁNEZ, A., CUADRADO, A., MARTEL, O., AFONSO, H., MONOPOLI, D. (2018). Gyroid porous titanium structures: A versatile solution to be used as scaffolds in bone defect reconstruction. In: Materials \& Design, Vol. 140, pp. 21-29.

[14] CHEN, S. Y., HUANG, J. C., PAN, C. T., LIN, C. H., YANG, T. L., HUANG, Y. S., OU, C. H., CHEN, L. Y., LIN, D. Y., LIN, H. K., LI, T. H., JANG, J. S. C., and YANG, C. C. (2017). Microstructure and mechanical properties of open-cell porous Ti-6Al-4V fabricated by selective laser melting. In: Journal of Alloys and Compounds, Vol. 713, pp. 248-254.

[15] VAN BAEL, S., CHAI, Y. C., TRUSCELLO, S., MOESEN, M., KERCKHOFS, G., VAN OOSTERWYCK, H., KRUTH, J. P., SCHROOTEN, J. (2012). The effect of pore geometry on the in vitro biological behavior of human periosteum-derived cells seeded on selective laser-melted Ti6Al4V bone scaffolds. In: Acta Biomaterialia, Vol. 8, No. 7, pp. 2824-2834.

[16] LI, Y., ZHOU, J., PAVANRAM, P., LEEFLANG, M. A., FOCKAERT, L. I., POURAN, B., TÜMER, N., SCHRÖDER, K.
U., MOL, J. M. C., WEINANS, H., JAHR, H., and ZADPOOR, A. A. (2018). Additively manufactured biodegradable porous magnesium. In: Acta Biomaterialia, Vol. 67, pp. 378-392.

[17] RAN, Q., YANG, W., HU, Y., SHEN, X., YU, Y., XIANG, Y., CAI, K. (2018). Osteogenesis of 3D printed porous Ti6Al4V implants with different pore sizes. In: Journal of the Mechanical Behavior of Biomedical Materials, Vol. 84, pp. 1-11.

[18] TANIGUCHI, N., FUJIBAYASHI, S., TAKEMOTO, M., SASAKI, K., OTSUKI, B., NAKAMURA, T., MATSUSHITA, T., KOKUBO, T., MATSUDA, S. (2016). Effect of pore size on bone ingrowth into porous titanium implants fabricated by additive manufacturing: An in vivo experiment. In: Materials Science and Engineering: C, Vol. 59, pp. 690-701.

[19] WEIBMANN, V., DRESCHER, P., BADER, R., SEITZ, H., HANSMANN, H., LAUFER, N. (2017). Comparison of Single Ti6Al4V Struts Made Using Selective Laser Melting and Electron Beam Melting Subject to Part Orientation. In: Metals, Vol. 7, No. 3, pp. 91.

[20] PEREZ-SANCHEZ, A., YÁNEZ, A., CUADRADO, A., MARTEL, O., NUNO, N. (2018). Fatigue behaviour and equivalent diameter of single Ti-6Al-4V struts fabricated by Electron Bean Melting orientated to porous lattice structures. In: Materials \& Design, Vol. 155, pp. 106-115.

[21] SUARD, M., MARTIN, G., LHUISSIER, P., DENDIEVEL, R., VIGNAT, F., BLANDIN, J. J., VILLENEUVE, F. (2015). Mechanical equivalent diameter of single struts for the stiffness prediction of lattice structures produced by Electron Beam Melting. In: Additive Manufacturing, Vol. 8, pp. 124-131.

[22] KRAGSTRUP, J., MELSEN, F., MOSEKILDE, L. (1983). Thickness of bone formed at remodeling sites in normal human iliac trabecular bone: variations with age and sex. In: Metabolic Bone Disease and Related Research, Vol. 5, No. 1, pp. 17-21.

[23] BARAK, M. M., SHERRATT, E., LIEBERMAN, D. E. (2016) Trabecular orientation in the 3rd metacarpal head of humans and chimps reveals their difference in locomotion behavior. In: American journal of physical anthropology, Vol. 159, No. S62, p. 86.

[24] YAN, C., HAO, L., HUSSEIN, A., YOUNG, P. (2015). Ti-6Al-4V triply periodic minimal surface structures for bone implants fabricated 
via selective laser melting. In: Journal of the Mechanical Behavior of Biomedical Materials, Vol. 51, pp. 61-73.

[25] CAMPANELLI, S. L., CONTUZZI, N., LUDOVICO, A. D., CAIAZZO, F., CARDAROPOLI, F., SERGI, V. (2014). Manufacturing and Characterization of Ti6Al4V Lattice Components Manufactured by Selective Laser Melting. In: Materials, Vol. 7, No. 6, pp. 4803-4822.

[26] GU, D., SHEN, Y. (2007). Balling phenomena during direct laser sintering of multi-component Cu-based metal powder. In: Journal of Alloys and Compounds, Vol. 432, No. 1, pp. 163-166.

[27] RIEDLBAUER, D., SCHAROWSKY, T., SINGER, R. F., STEINMANN, P., KÖRNER, C., MERGHEIM, J. (2017). Macroscopic simulation and experimental measurement of melt pool characteristics in selective electron beam melting of Ti-6Al-4V. In: The International Journal of Advanced Manufacturing Technology, Vol. 88, No. 5-8, pp. 1309-1317.

[28] YVES, H., FELIX, P. (2018). Process Monitoring of Laser Beam Melting. In: Laser Technik Journal, Vol. 15, No. 2, pp. 54-57.

[29] ZHANG, B., LI, Y., BAI, Q. (2017). Defect Formation Mechanisms in Selective Laser Melting: A Review. In: Chinese Journal of Mechanical Engineering, Vol. 30, No. 3, pp. 515-527.

[30] KABIR, M. R., RICHTER, H. (2017). Modeling of Processing-Induced Pore Morphology in an Additively-Manufactured Ti-6Al-4V Alloy. In: Materials, Vol. 10, No. 2, pp. 145.
[31] SU, X., YANG, Y. (2012). Research on track overlapping during Selective Laser Melting of powders. In: Journal of Materials Processing Technology, Vol. 212, No. 10, pp. 2074-2079.

[32] HANZL, P., $\quad$ ZETKOVA, I.,CAJTHAMLOVA, S. (2019). Influence of Strut Diameter and Building Direction on Strength of Lattice Structure. In: Manufacturing Technology, Vol. 19, No. 6, pp. 947-951.

[33] YANG, S., LEONG, K. F., DU, Z., CHUA, C. K. (2001). The design of scaffolds for use in tissue engineering. Part I. Traditional factors. In: Tissue Engineering, Vol. 7, No. 6, pp. 679-689.

[34] CAPEK, J., MACHOVA, M., FOUSOVA, M., KUBASEK, J., VOJTECH, D., FOJT, J., JABLONSKA, E., LIPOV, J., RUML, T. (2016). Highly porous, low elastic modulus 316L stainless steel scaffold prepared by selective laser melting. In: Materials Science and Engineering: C, Vol. 69, pp. 631-639.

[35] ATTAR, H., LÖBER, L., FUNK, A., CALIN, M., ZHANG, L. C., PRASHANTH, K. G., SCUDINO, S., ZHANG, Y. S., ECKERT, J. (2015). Mechanical behavior of porous commercially pure $\mathrm{Ti}$ and $\mathrm{Ti}-\mathrm{TiB}$ composite materials manufactured by selective laser melting. In: Materials Science and Engineering: A, Vol. 625, pp. 350-356.

[36] WU, S., LIU, X., YEUNG, K. W. K., LIU, C., YANG, X. (2014). Biomimetic porous scaffolds for bone tissue engineering. In: Materials Science and Engineering: R: Reports, Vol. 80, pp. 1-36. 